\title{
BMJ Open Pregnancy exposure to air pollution and early childhood respiratory health in the Norwegian Mother and Child Cohort Study (MoBa)
}

\author{
Christian Madsen, ${ }^{1}$ Siri Eldevik Haberg, ${ }^{2}$ Maria C Magnus, ${ }^{3}$ Geir Aamodt, ${ }^{4}$ \\ Hein Stigum, ${ }^{3,5}$ Stephanie J London, ${ }^{6}$ Wenche Nystad, ${ }^{3}$ Per Nafstad ${ }^{3,5}$
}

To cite: Madsen C, Haberg SE, Magnus MC, et al. Pregnancy exposure to air pollution and early childhood respiratory health in the Norwegian Mother and Child Cohort Study (MoBa). BMJ Open 2017;7:e015796. doi:10.1136/ bmjopen-2016-015796

\section{- Prepublication history for} this paper is available online. To view these files please visit the journal online (http://dx.doi org/10.1136/bmjopen-2016015796).

Received 16 January 2017 Revised 1 August 2017 Accepted 4 August 2017
CrossMark

For numbered affiliations see end of article.

Correspondence to Dr Christian Madsen; christian.madsen@fhi.no

\section{ABSTRACT}

Objectives It is unclear whether maternal air pollution exposure during pregnancy induces changes in the developing respiratory system of a child and whether it has consequences for respiratory health in early childhood. We investigated associations between exposure to moderate levels of air pollution during pregnancy and early childhood lower respiratory tract infections (LRTI) and wheezing. Methods This study used a subgroup of 17533 participants in the Norwegian Mother and Child Cohort Study. Air pollution levels at residential addresses were estimated using land use regression models, and backextrapolated to the period of each pregnancy. Information on LRTI and wheezing and lifestyle factors was collected from questionnaires completed by mothers during pregnancy and when the child was 6 and 18 months of age.

Results Moderate mean levels of $\mathrm{NO}_{2}\left(13.6 \mu \mathrm{g} / \mathrm{m}^{3}\right.$, range 0.01-60.4) exposure at residential address during pregnancy were not statistically associated with LRTI and wheezing. No association was found per $10 \mu \mathrm{g} / \mathrm{m}^{3}$ change in $\mathrm{NO}_{2}$ exposure and LRTI before the age of 6 months (adjusted risk ratio (RR) $0.99 ; 95 \% \mathrm{Cl} 0.84$ to 1.17 ), or between 6 and 18 months of age (adjusted RR 1.05; $95 \% \mathrm{Cl} 0.94$ to 1.16). Similarly, we found no association per $10 \mu \mathrm{g} / \mathrm{m}^{3}$ change in $\mathrm{NO}_{2}$ exposure and wheezing between 6 and 18 months of age (adjusted RR 1.02; $95 \% \mathrm{Cl} 0.97$ to 1.07 ).

Conclusions There were no statistically significant associations for moderate levels of pregnancy $\mathrm{NO}_{2}$ exposure and respiratory health outcomes during early childhood in overall analyses.

\section{INTRODUCTION}

There is increasing evidence from both experimental and epidemiological studies that the prenatal period is a critical window for harmful effects from different types of exposures on respiratory health. ${ }^{1}$ Lower respiratory tract infections (LRTI) are common in infants and young children. ${ }^{2}$ They are caused primarily by viral pathogens and are clinically expressed as bronchiolitis or pneumonia. ${ }^{2}$ Childhood wheeze is a symptom of
Strengths and limitations of this study

- Large prospective cohort with data on lower respiratory tract infections, with additional linked data from medical birth registry.

- Land use regression-modelled traffic exposure assessment at residential address using both spatial and temporal adjustment.

- Cohort living in areas with low to moderate air pollution concentrations.

- Unable to account for any changes in address location and pollution exposure during pregnancy.

several heterogeneous conditions, and may occur during viral respiratory infections or be associated with atopy. ${ }^{3}$ Infections and wheeze are also closely related in young children. Respiratory diseases in early childhood may have long-term consequences, accounting for a significant proportion of adult lung disease. ${ }^{24}$ Special attention should be given to modifiable factors that may influence lung development at crucial stages (prenatally and postnatally). Numerous epidemiological studies have shown that children exposed to tobacco smoke or higher levels of ambient air pollution above recommended levels (eg, standards from the European Union (EU) or the WHO) are more prone to develop respiratory disorders. ${ }^{5-7}$ Air pollution may affect the lungs by inducing low-grade systemic inflammation and oxidative stress, ${ }^{8}$ leading to pathological changes in the respiratory system. Children are particularly susceptible due to the continuous development of lungs that takes place from embryogenesis to early adolescence, ${ }^{49}$ and continuous immune system development. ${ }^{10}$ Of particular interest is intrauterine exposure, where air pollution may indirectly affect the developing lung tissue of the fetus. ${ }^{11} 12$ 
There is an ongoing interest in whether exposure to ambient air pollution during pregnancy might influence respiratory health in early childhood. ${ }^{13}$ The effect of air pollution exposure during pregnancy on respiratory health and allergic responses early in life has been examined by several studies with large heterogeneity. ${ }^{14-19}$ Some studies report associations of prenatal air pollution exposure with LRTI in early childhood. ${ }^{14-17}$ Other studies have found no support for an association between air pollution exposure and LRTI in early childhood. ${ }^{18}{ }^{19}$ In addition, there are animal exposure studies that have identified both anatomic/mechanical and immunological mechanisms by which air pollution exposure may increase susceptibility of the respiratory system to infections. ${ }^{20} 21$

In this study, we investigated the associations between estimated exposure to traffic-related air pollution during pregnancy and early childhood respiratory health (LRTI and wheeze) in selected urban and county areas of Norway. Norway is characterised by relatively low levels of air pollution, ${ }^{22}$ and it is of interest whether low levels might interfere with intrauterine respiratory system development and affect respiratory health later in life.

\section{METHODS}

\section{Study population}

The Norwegian Mother and Child Cohort Study (MoBa) is a prospective, population-based pregnancy cohort study conducted by the Norwegian Institute of Public Health. ${ }^{22}$ Pregnant women were recruited from all over Norway from 1999 to 2008. Among invited women, 41\% consented to participate. Mothers could participate with more than one child, resulting in 114500 children and 95 200 mothers included in the cohort.

All participants living in our study areas (Oslo, Bergen, Akershus and Hordaland) were eligible for our study $(\mathrm{n}=22$ 149, 23.3\%). We excluded participants with missing $\mathrm{NO}_{2}$ exposure information ( $\mathrm{n}=3$ 876), multiple births $(n=664)$ and non-live births $(n=76)$. Only data on singleton live births were used in the analyses. The total number of participants from the four study areas was 17 $533(79 \%)$. Pregnancy-related information was obtained from the Medical Birth Registry of Norway (MBRN).

Mothers participating in the MoBa study completed a number of questionnaires during follow-up. We used data on lifestyle characteristics from the first questionnaire completed at recruitment (approximately at weeks 17-18 of pregnancy) and another questionnaire completed at week 30 of pregnancy. Information on the respiratory outcomes was collected from maternal questionnaires completed when the child was 6 and 18 months of age. The children were born from 2001 to 2009, 14386 mothers had returned the questionnaire at 6 months, and 12231 had returned the questionnaire at 18 months (table 1).

The study was approved by the regional ethics committee and the Norwegian Data Inspectorate. The current study is based on versions VI (pregnancy data) and VIII (respiratory outcomes) of the quality-assured data files released for research on 15 April 2011 and on 14 February 2014, respectively.

\section{Outcomes and covariates}

The outcomes, LRTI and wheeze, were based on the maternal report from questionnaires filled when children were 6 and 18 months of age. The questionnaires can be viewed at the MoBa website (https://www.fhi.no/ en/studies/moba/). LRTIs included respiratory syncytial virus, bronchiolitis, bronchitis and pneumonia. We classified hospitalisation for any of these conditions as being hospitalised for LRTI at (1) between 0 and 6 months of age, and (2) between 6 and 18 months of age. Wheeze was defined as 'wheezing/whistling in the chest' or 'tightness in the chest' between 6 and 18 months of age. The outcomes were treated as dichotomous.

The following characteristics were extracted from the MBRN: parity defined as number of previous deliveries $(0,1, \geq 2)$, mother's age at birth (years), marital status (married/cohabiting, other) sex of the child (boy, girl) and year of birth. Questionnaire information was used to determine maternal education (less than high school, high school, up to 4 years of college, more than 4 years of college (master or professional degree)), maternal smoking during pregnancy (never, any smoking during pregnancy), maternal weight at the beginning of pregnancy $(\mathrm{kg})$ and maternal height $(\mathrm{m})$ used to calculate body mass index (BMI) (maternal weight divided by squared maternal height), and maternal atopy (ever having hay fever, pollen allergy, atopic dermatitis, allergy to animal hair, other types of allergy or asthma).

Adjustment variables (table 1) were selected based on literature analyses and included maternal age at delivery, maternal marital status, maternal education, sex of child, maternal prepregnancy BMI, parity, year of birth, smoking during pregnancy, maternal atopy and area.

\section{Air pollution exposure}

In this study, we used land use regression (LUR)-modelled exposure to traffic-related pollutant $\mathrm{NO}_{2}$ at the residential address at the time of delivery for women included in MoBa. Separate models were developed for four of the recruitment areas: the two biggest cities in Norway (Oslo and Bergen) and their surrounding counties (Akershus and Hordaland). ${ }^{23}$

Estimates of air pollution exposure during pregnancy were based on the methodology developed for the European Study of Cohorts for Air Pollution Effects (ESCAPE) project. ${ }^{24}{ }^{25}$ LUR models for $\mathrm{NO}_{2}$ levels were built for each of the studied areas in order to account for regional specifics. $^{23}$ Sampling of air pollution is done retrospectively since it was not part of the MoBa design. We measured the spatial distribution of air pollution for Oslo and Akershus in 2010 and for Bergen and Hordaland in 2011. Measurement campaigns included three rounds of approximately 2 weeks' duration with $\mathrm{NO}_{2}$ measurements (during winter, summer and an intermediate season) 
Table 1 Descriptive statistics for study participants from the MoBa cohort

\begin{tabular}{|c|c|c|c|}
\hline & $\begin{array}{l}\text { Baseline cohort at birth with } \\
\mathrm{NO}_{2} \text { data }(\mathrm{n}=17533)\end{array}$ & $\begin{array}{l}\text { Questionnaire at } 6 \text { months } \\
(n=14386)\end{array}$ & $\begin{array}{l}\text { Questionnaire at } 18 \text { months } \\
(n=12 \text { 231) }\end{array}$ \\
\hline Oslo & 4669 (26.6) & 3801 (26.4) & $3320(27.1)$ \\
\hline Akershus & $7554(43.1)$ & $6284(43.7)$ & $5350(43.7)$ \\
\hline Bergen & $3869(22.1)$ & $3135(21.8)$ & $2591(21.2)$ \\
\hline Hordaland & $1441(8.2)$ & $1166(8.1)$ & $970(7.9)$ \\
\hline LRTI 0-6 months & & $653(4.5)$ & \\
\hline Missing & & $500(3.5)$ & \\
\hline LRTI 6-18 months & & & $1469(12.0)$ \\
\hline Missing & & & $230(1.9)$ \\
\hline Wheeze $6-18$ months & & & $4961(40.6)$ \\
\hline Missing & & & $255(2.1)$ \\
\hline $\begin{array}{l}\text { Women who changed address } \\
\text { during pregnancy }\end{array}$ & $2336(13.3)$ & $1782(12.4)$ & $1471(12.0)$ \\
\hline \multicolumn{4}{|l|}{ Parity } \\
\hline 0 & $8310(47.4)$ & $6973(48.5)$ & $6003(49.1)$ \\
\hline 1 & $6328(36.1)$ & $5138(35.7)$ & $4310(35.2)$ \\
\hline$\geq 2$ & $2895(16.5)$ & $2275(15.8)$ & $1918(15.7)$ \\
\hline \multicolumn{4}{|l|}{ Sex of child } \\
\hline Boy & $8925(50.9)$ & $7285(50.6)$ & $6177(50.5)$ \\
\hline Girl & $8608(49.1)$ & $7101(49.4)$ & $6054(49.5)$ \\
\hline Maternal age at delivery, years & $31.0 \pm 4.5$ & $31.1 \pm 4.4$ & $31.2 \pm 4.3$ \\
\hline \multicolumn{4}{|l|}{ Marital status } \\
\hline Married/cohabiting & $16780(95.7)$ & $13839(96.2)$ & 11797 (96.5) \\
\hline Other & $753(4.3)$ & $547(3.8)$ & $434(3.6)$ \\
\hline \multicolumn{4}{|l|}{ Maternal education } \\
\hline Less than high school & $986(5.6)$ & $713(5.0)$ & $547(4.5)$ \\
\hline High school & $4175(23.8)$ & $3465(24.1)$ & $2845(23.3)$ \\
\hline Up to 4 years of college & $6480(37.0)$ & $5677(39.5)$ & $4919(40.2)$ \\
\hline $\begin{array}{l}\text { More than } 4 \text { years of college } \\
\text { (master or professional } \\
\text { degree) }\end{array}$ & $4867(27.8)$ & $4254(29.6)$ & $3731(30.5)$ \\
\hline Missing & 1025 (5.9) & $277(1.9)$ & $189(1.6)$ \\
\hline $\begin{array}{l}\text { Maternal smoking during } \\
\text { pregnancy }\end{array}$ & $1085(6.2)$ & $843(5.9)$ & $675(5.5)$ \\
\hline Missing & $1000(5.7)$ & $263(1.8)$ & $185(1.5)$ \\
\hline $\begin{array}{l}\text { Maternal prepregnancy body } \\
\text { mass index* }\end{array}$ & $23.5 \pm 3.8$ & $23.5 \pm 3.7$ & $23.5 \pm 3.7$ \\
\hline Maternal atopy & $5802(33.1)$ & $4947(34.4)$ & $4276(35.0)$ \\
\hline \multicolumn{4}{|l|}{ Season of birth } \\
\hline Winter & $4099(23.4)$ & $3352(23.3)$ & $2858(23.4)$ \\
\hline Spring & $4686(26.7)$ & $3851(26.8)$ & $3191(26.1)$ \\
\hline Summer & $4630(26.4)$ & $3827(26.6)$ & $3312(27.1)$ \\
\hline Autumn & 4118 (23.5) & 3356 (23.3) & 2870 (23.5) \\
\hline
\end{tabular}

Numbers are $\mathrm{n}(\%)$ or mean \pm SD deviation.

${ }^{*}$ Missing data for maternal prepregnancy body mass index: baseline cohort 1549 (8.8\%), at 6 months 693 (4.8\%), at 18 months 522 (4.3\%).

LRTI, lower respiratory tract infections; MoBa, Norwegian Mother and Child Cohort Study. 
within a 1-year period. Measurement sites (14 in Oslo, 36 in Akershus and 46 in Bergen/Hordaland) were selected to represent the range of residential exposure for each study area. In the analyses, we included sites with no missing data and no geocoding mismatches. The models provided adjusted $\mathrm{R}^{2}$ in the range of $55 \%-85 \%$, and more details of these models are described elsewhere. ${ }^{23}$

LUR models were built separately for Oslo and Akershus. Only one model was built for the whole Hordaland county (including the city Bergen) due to a low number of valid measurement sites outside Bergen. Predictors for building the LUR model were obtained from a geographical information system (GIS) analyses of the N50 and VBASE maps (received in February 2013) providing information on land use, residential density, types of landscape and road network information. We built multiple linear regression models and performed diagnostic model tests according to the method described by Beelen and colleagues. ${ }^{24}$

Yearly means of air pollution levels at residential address at birth were estimated using the resulting LUR models. Variables in models were truncated in accordance to the range of corresponding variables used for LUR model building. Negative modelled values were replaced with 0.01 to avoid the unlikely scenario of negative modelled exposure and keep these in the analyses as low-exposed addresses $(n=112){ }^{23}$ The true exposure from $\mathrm{NO}_{2}$ at these addresses are most likely at the low end of the scale. In order to account for temporal variability, we used the ratio method of back-extrapolation to the period of each pregnancy using continuous routine monitoring station data. ${ }^{25}$ Daily $\mathrm{NO}_{2}$ measurements were obtained from the Norwegian Institute for Air Research database 'Luftkvalitet.info' for the period 2000-2012 in Oslo (used for Oslo and Akershus), and for the period 2003-2012 in Bergen (used for Bergen and Hordaland). Daily estimates of exposure were calculated using the ratio method of back-extrapolation: the LUR-modelled yearly estimate multiplied by the ratio between daily $\mathrm{NO}_{2}$ routine monitoring station measurement and an annual average for the year when LUR measurement campaign took place. Daily $\mathrm{NO}_{2}$ exposure estimates were averaged separately for first, second and third trimester, and also over the whole pregnancy.

\section{Statistical analysis}

Generalised linear models were fitted to evaluate the associations between pregnancy $\mathrm{NO}_{2}$ exposure and respiratory outcomes. Results are presented for crude and adjusted models as risk ratios (RR) with robust SEs. Multiplicative interactions were tested in the adjusted models between the continuous $\mathrm{NO}_{2}$ pregnancy exposure variable and the following categorical variables: area, sex, smoking during pregnancy, parity, birth season and maternal atopy.

Sensitivity analyses were performed by (1) restricting the analyses to women who did not change address during pregnancy, and (2) restricting the analyses to pregnancies during the last period (2006-2008) of the
MoBa recruitment, thus closer in time to the exposure campaign and GIS variables.

Area variable was defined by the location of the address at delivery: Oslo, Akershus, Bergen and Hordaland. In a previous study, the area variable was found to be an important factor in attenuating the associations between exposure and birth outcome in $\mathrm{MoBa} .{ }^{23}$ These differences by area could be linked to more travel to and from work and to other activities, visiting the central, more polluted parts of the city by, for example, higher educated women and for city dwellers per se. This variable is included in the adjusted models since it previously has been reported to be a potential proxy for unmeasured factors that could vary between each study area and thus could influence the outcome variables within each separate area. Still, area may also reflect the spatial distribution of air pollution, and thus result in overadjustment bias on the path between exposure and outcome. ${ }^{26}$ We therefore performed a separate post hoc analysis by excluding the area variable from the adjusted model. In addition, we performed exploratory analyses post hoc by area, sex of child, parity, season of birth and maternal atopy.

We used ArcGIS V.10.1 software (Esri, Redlands, California, USA) for GIS analyses; statistical analyses were performed using Stata V.13.0.

\section{RESULTS}

The study population included in this study consisting of participants from the four study areas of Norway with pregnancy air pollution exposure data had similar characteristics as the whole MoBa cohort study with information from 6 months and at 18 months (table 1). A total of $4.5 \%$ of children had LRTI between 0 and 6 months of age, and 12\% of children had LRTI between 6 and 18 months of age. A total of $40.6 \%$ of the children had wheezing symptoms between 6 and 18 months of age.

The majority $(86.7 \%)$ of women did not change address during pregnancy. Maternal smoking in pregnancy was relatively uncommon (6.2\%). Maternal atopy was reported in $33.1 \%$ of women (table 1). The distribution of the study population across birth seasons reflects the timing of recruitment into $\mathrm{MoBa}$, and we therefore observe slight deviation from the equal seasonal distribution.

The mean $\mathrm{NO}_{2}$ exposure during the whole pregnancy was $13.6 \pm 6.9 \mu \mathrm{g} / \mathrm{m}^{3} \mathrm{NO}_{2}$, which is well below the $\mathrm{EU}$ air quality yearly average standard of $40 \mu \mathrm{g} / \mathrm{m}^{3} \mathrm{NO}_{2}$. The range of $\mathrm{NO}_{2}$ spanned from 0.01 through $60.4 \mu \mathrm{g} / \mathrm{m}^{3}$, with a total of 27 children with concentrations equal or above $40 \mu \mathrm{g} / \mathrm{m}^{3}$ at their residential address. Exposures by trimester and the whole pregnancy exposure (table 2) were highly correlated ( $\mathrm{r}=0.73$ to 0.85 ). We therefore decided to use only the average $\mathrm{NO}_{2}$ exposure during the whole pregnancy as our exposure estimate in the analyses.

We found no associations of $\mathrm{NO}_{2}$ exposure during pregnancy with LRTI at $0-6$ months, LRTI at $6-18$ months or wheeze at 6-18 months in the overall analyses (table 3 ). 
Table 2 LUR-modelled air pollution exposure using residential address at time of birth: exposure during the whole pregnancy and by trimester

\begin{tabular}{lccccc}
\hline & $\begin{array}{l}\text { Oslo } \\
\mathbf{n = 4 6 6 9}\end{array}$ & $\begin{array}{l}\text { Akershus } \\
\mathbf{n = 7} \mathbf{5 5 4}\end{array}$ & $\begin{array}{l}\text { Bergen } \\
\mathbf{n = 3} \mathbf{8 6 9}\end{array}$ & $\begin{array}{l}\text { Hordaland } \\
\mathbf{n = 1 4 4 1}\end{array}$ & $\begin{array}{l}\text { Total } \\
\mathbf{n = 1 7} \mathbf{5 3 3}\end{array}$ \\
\hline Mean LUR-modelled $\mathrm{NO}_{2}$ exposure $\left(\mu \mathrm{g} / \mathrm{m}^{3}\right)$ & & & & \\
Whole pregnancy & $21.6 \pm 4.4$ & $10.3 \pm 3.8$ & $13.2 \pm 6.2$ & $6.3 \pm 4.3$ & $13.6 \pm 6.9$ \\
Trimester 1 & $21.7 \pm 6.1$ & $10.2 \pm 4.2$ & $13.4 \pm 6.4$ & $6.5 \pm 4.4$ & $13.7 \pm 7.4$ \\
Trimester 2 & $22.0 \pm 6.1$ & $10.4 \pm 4.3$ & $13.3 \pm 6.5$ & $6.3 \pm 4.3$ & $13.8 \pm 7.5$ \\
Trimester 3 & $21.5 \pm 6.1$ & $10.3 \pm 4.2$ & $13.1 \pm 6.3$ & $6.3 \pm 4.3$ & $13.6 \pm 7.3$ \\
\hline
\end{tabular}

Numbers are mean \pm SD deviation.

European Union air quality standard for $\mathrm{NO}_{2}: 1$-year average $40 \mu \mathrm{g} / \mathrm{m}^{3}$.

LUR, land use regression.

The main covariates affecting the change in significance of RR estimate from the crude to the adjusted models were parity and area. In the stratified analyses by area we observed a consistent pattern, although not statistically significant, of positive associations for LRTI and wheeze for participants living outside big cities, in Akershus and Hordaland (table 3). An analysis of the cumulative incidence of LRTI (0-18 months of age) was equal to an $\mathrm{RR}=1.04$ (95\% CI 0.93 to 1.17 ).

There was no evidence of effect modification by the adjustment variables. Stratified analyses post hoc by maternal atopy status and birth season did not identify any important differences between the groups. No statistically significant interactions were detected between

Table 3 Associations between pregnancy exposure to $\mathrm{NO}_{2}$ and respiratory health of children by age 6 and 18 months

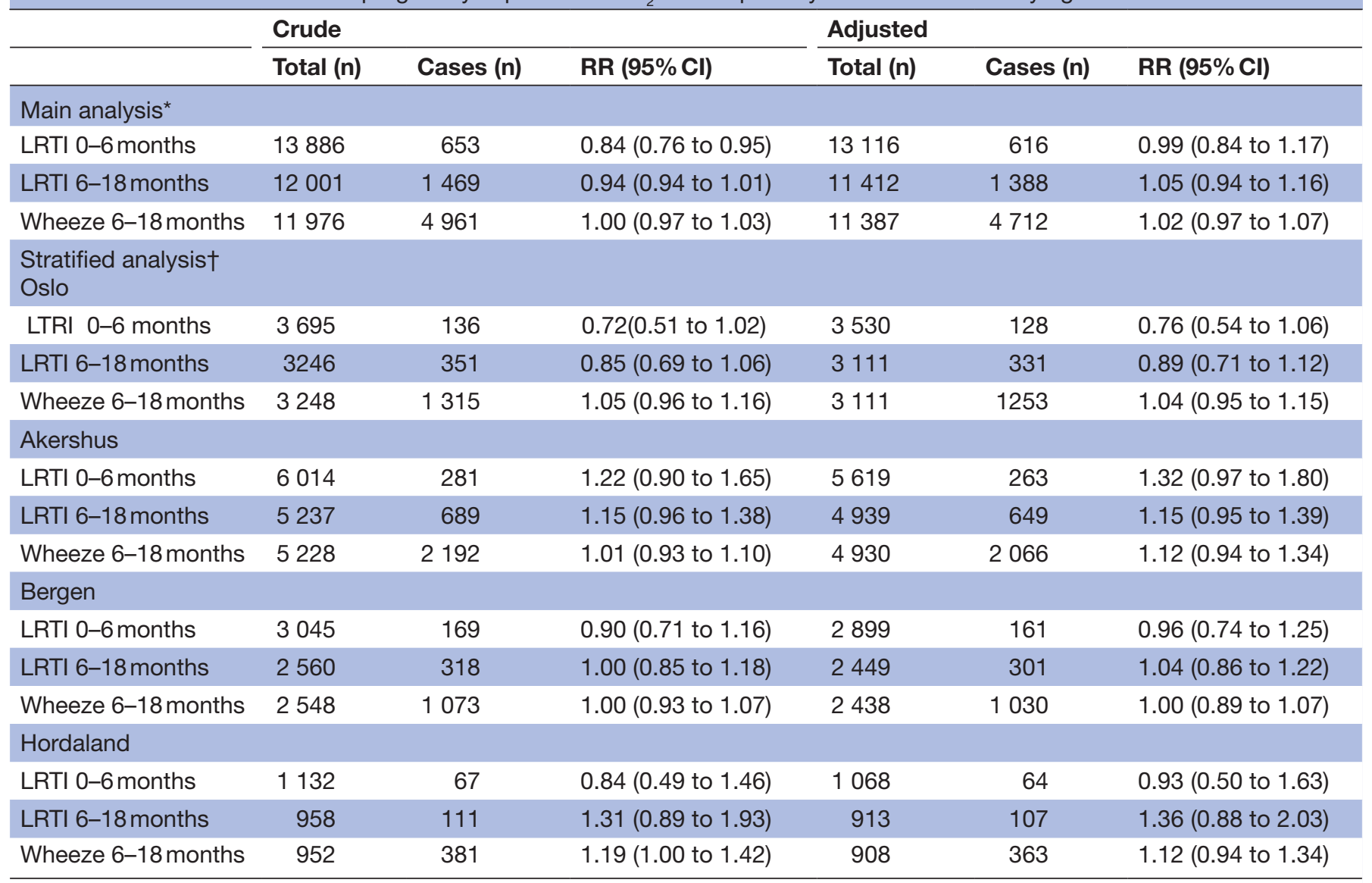

Effect estimates per $10 \mu \mathrm{g} / \mathrm{m}^{3} \mathrm{NO}_{2}$.

${ }^{*}$ Adjusted for maternal age at delivery, years of birth, maternal marital status, maternal education, sex of child, maternal prepregnancy BMI, smoking during pregnancy, parity, maternal atopy and study area.

†Adjusted for maternal age at delivery, year of birth, maternal marital status, maternal education, sex of child, maternal prepregnancy BMI, smoking during pregnancy, parity and maternal atopy.

$\mathrm{BMI}$, body mass index; LRTI, lower respiratory tract infections; RR, risk ratio. 
$\mathrm{NO}_{2}$ exposure and maternal atopy, sex of child, area, birth season or parity. Sensitivity analyses resulted in no substantial changes compared with the reported results. Excluding from the adjustment set the area variable, as a factor potentially reflecting spatial distribution of air pollution, did not considerably change the results. Restricting the analyses to pregnancies during the last period of the MoBa recruitment (2006-2008) did not result in substantial changes to the reported results.

\section{DISCUSSION}

In this study, we found no statistically significant associations for pregnancy $\mathrm{NO}_{2}$ exposure to traffic-related air pollution exposure at residential address at birth and LRTI or wheeze in early childhood.

A previous study by Esplugues and colleagues has reported similar results of no association between LUR-modelled prenatal $\mathrm{NO}_{2}$ exposure (with higher than in our study whole pregnancy mean $\mathrm{NO}_{2}$ values of $39.1 \mu \mathrm{g} / \mathrm{m}^{3}$ ) with LRTI or persistent cough during the first year of life, but they did report an association between postnatal $\mathrm{NO}_{2}$ exposure and persistent cough. ${ }^{18}$ In the large international ESCAPE study, uniting cohorts from Germany, Sweden, the Netherlands and the UK, decrease in lung function parameters has been associated with exposure to LUR-modelled annual average $\mathrm{NO}_{2}, \mathrm{NO}_{\mathrm{x}}, \mathrm{PM}_{2.5}$ absorbance and $\mathrm{PM}_{2.5}$ at current address at $6-8$ years of age, but not at birth address. ${ }^{27}$

We found some indication of different patterns for associations between prenatal air pollution exposure and early respiratory health in study participants living in cities versus counties outside cities. Associations between prenatal air pollution exposure and the respiratory outcomes were overall greater in the non-urban areas, although the estimates were not statistically significant. This might be due to a higher misclassification of exposure in cities because of higher mobility (change of residential address) or due to other types of pollutants in non-urban areas. ${ }^{28} \mathrm{~A}$ study by Canfield and colleagues ${ }^{29}$ reported higher mobility for nulliparous women as compared with women with several children. They explained this as related to the need for larger homes due to expecting a child (first born) and a need to live closer to healthcare facilities. ${ }^{29} \mathrm{~A}$ previous study from Norway reported that half of the mothers work during pregnancy and that no difference was found when comparing using only home address with a weighted exposure of home and work address exposure. ${ }^{30}$ On the other hand, non-city population might have more homogeneous exposure and spend more time close to home. Difference in distribution of socioeconomic factors or parity might play a role: families with several children tend to move out of large cities in Norway. Familiar predisposition to allergic disorders may be an important factor in modifying the effect of tobacco smoke exposure on wheezing. ${ }^{31}$ Certain months of birth, due to their correlation with viral infections seasons, can be a risk factor for wheezing and LRTI. ${ }^{3}{ }^{32}$ Our study found no differences in the effect from groups divided by maternal atopy status or birth season.
Our study applied standardised individual exposure assessment for the large study population, and detailed information on potential confounders was collected from prenatal questionnaires. Estimates for prenatal exposure to $\mathrm{NO}_{2}$ were based on LUR models and temporal back-extrapolation of exposure during the entire pregnancy at the address at birth. The $\mathrm{NO}_{2}$ exposure was collected during 2010 and 2011, and the GIS variables used in the modelling were collected in 2013. The modelled exposures at each address were back-extrapolated using fixed 24-hour monitoring data from each area in the period 1999-2009. Such estimates might be a subject to non-differential misclassification of exposure due to changes in GIS variables, or differences in participants' mobility and lifestyle factors. However, results of the sensitivity analyses only in women who did not change address during pregnancy were similar to the overall analyses. Likewise, restricting the analyses to pregnancies during the last period, closer in time to the collected exposure variables and GIS variables, did not result in different associations from the overall analyses.

In epidemiological studies investigating air pollution effects, precision of exposure estimation is an important challenge. It is usually not feasible to sample personal air pollution exposure in large birth cohorts, mainly due to the amount of participants needed and due to the fact of not having information about the pregnancy before week 17. It has therefore become increasingly common to apply modelling of air pollution exposure at individual residential addresses, such as dispersion models and LUR models. High correlations have previously been reported between indoor and outdoor concentrations of $\mathrm{NO}_{2},{ }^{33}$ and $\mathrm{NO}_{2}$ is also reported to display higher spatial variation as compared with other pollutants, ${ }^{34}$ thus making it a better proxy for individual air pollution exposure.

The mean air pollution exposure levels explored in this study may be relatively low for detecting the association between prenatal exposure and postnatal respiratory health, and the reported effect estimates might be biased towards null due to non-differential misclassification of exposure. It could also be difficult to disentangle prenatal and early postnatal exposure to air pollution if family continues to live at the same address at these two periods. Prenatal exposures need to be carefully studied for identifying potential critical windows of exposure. In our data, exposures by trimester were highly correlated with whole pregnancy exposure, and therefore we only assessed the exposure during entire pregnancy. More studies are needed to explore the causative association between prenatal air pollution exposure and respiratory health early in childhood, and to characterise critical time windows and main pollutants that are involved in pathological changes. Of interest for future research is the sex difference in prenatal exposure effect identified in our study.

In this large Norwegian pregnancy cohort we found no statistically significant associations for moderate levels of exposure to $\mathrm{NO}_{2}$ during pregnancy and childhood respiratory health measured by LRTI and wheeze. 
Author affiliations

${ }^{1}$ Department of Health \& Inequality, Norwegian Institute of Public Health, Oslo, Norway

${ }^{2}$ Domain for Mental and Physical Health, Norwegian Institute of Public Health, 0slo, Norway

${ }^{3}$ Department of Noncommunicable Diseases, Norwegian Institute of Public Health, Oslo, Norway

${ }^{4}$ Department of Landscape Architecture and Spatial Planning, Norwegian University of Life Sciences, As, Norway

${ }^{5}$ Department of Community Medicine and Global Health, Medical Faculty, University of Oslo, Oslo, Norway

${ }^{6}$ Department of Health and Human Services, National Institute of Environmental Health Sciences, National Institutes of Health, Research Triangle Park, North Carolina, USA

Acknowledgements The coauthors would like to express gratitude to all MoBa cohort participants and research team, to Sviatlana Panasevich and Jon Wickmann at NIPH for their help with the database management, and to the Norwegian Institute for Air Research team for providing valuable research data through their national air quality database. The authors also wants to thank the reviewers for their valuable comments.

Contributors PN, SJL, WN and MCM were involved in conception, hypothesis delineation and study design. SJL, GA, SEH and CM contributed to the exposure assessment. CM and PN drafted the manuscript. All authors were involved in data interpretation and approved the final submitted version of the manuscript.

Funding The Norwegian Mother and Child Cohort Study is supported by the Norwegian Ministry of Health and the Ministry of Education and Research, NIH/ NIEHS (contract no N01-ES-75558) and NIH/NIDS (grant no 1 U01NS 047537-01 and grant no 2 U01 NS 047537-06A1). This study was also supported by the Research Council of Norway (grant no 196102) and the Intramural Research Program of the NIH, National Institute of Environmental Health Sciences (project number Z01 ES49019).

Competing interests None declared.

Patient consent Obtained.

Ethics approval The Norwegian Mother and Child Cohort Study has approvals from the Regional Ethics Committee and the Norwegian Data Inspectorate. The current study is based on version VI of the quality-assured data files released for research on 15 April 2011

Provenance and peer review Not commissioned; externally peer reviewed.

Data sharing statement Technical description of the MoBa data can be found at the study website (https://www.fhi.no/en/studies/moba/). Researchers can apply for access to the data set (https://www.fhi.no/en/more/research--access-to-data/). Statistical code is available upon request from the corresponding author

Open Access This is an Open Access article distributed in accordance with the Creative Commons Attribution Non Commercial (CC BY-NC 4.0) license, which permits others to distribute, remix, adapt, build upon this work non-commercially, and license their derivative works on different terms, provided the original work is properly cited and the use is non-commercial. See: http://creativecommons.org/ licenses/by-nc/4.0/

(c) Article author(s) (or their employer(s) unless otherwise stated in the text of the article) 2017. All rights reserved. No commercial use is permitted unless otherwise expressly granted.

\section{REFERENCES}

1. Pinkerton KE, Joad JP. Influence of air pollution on respiratory health during perinatal development. Clin Exp Pharmacol Physiol 2006;33:269-72.

2. Graham NM. The epidemiology of acute respiratory infections in children and adults: a global perspective. Epidemiol Rev 1990;12:149-78.

3. Sherriff A, Peters TJ, Henderson J, et al. ALSPAC Study Team. Avon Longitudinal Study of Parents and Children. Risk factor associations with wheezing patterns in children followed longitudinally from birth to 3(1/2) years. Int J Epidemiol 2001;30:1473-84.

4. Merkus PJ. Effects of childhood respiratory diseases on the anatomical and functional development of the respiratory system. Paediatr Respir Rev 2003;4:28-39.
5. Carlsen $\mathrm{KH}$, Carlsen KC. Respiratory effects of tobacco smoking on infants and young children. Paediatr Respir Rev 2008;9:11-20.

6. Goldizen FC, Sly PD, Knibbs LD. Respiratory effects of air pollution on children. Pediatr Pulmonol 2016;51:94-108.

7. Maclntyre EA, Gehring $U$, Mölter A, et al. Air pollution and respiratory infections during early childhood: an analysis of 10 European birth cohorts within the ESCAPE Project. Environ Health Perspect 2014;122:107-13.

8. Brook RD, Rajagopalan S, Pope CA, et al. Particulate matter air pollution and cardiovascular disease: An update to the scientific statement from the American Heart Association. Circulation 2010;121:2331-78.

9. Pinkerton KE, Joad JP. Influence of air pollution on respiratory health during perinatal development. Clin Exp Pharmacol Physiol 2006;33:269-72.

10. Goenka A, Kollmann TR. Development of immunity in early life. J Infect 2015;71:S112-20.

11. Saenen ND, Plusquin M, Bijnens $E$, et al. In utero fine particle air pollution and placental expression of genes in the brain-derived neurotrophic factor signaling pathway: an ENVIRONAGE birth cohort study. Environ Health Perspect 2015;123:834-40.

12. Veras MM, Damaceno-Rodrigues NR, Caldini EG, et al. Particulate urban air pollution affects the functional morphology of mouse placenta. Biol Reprod 2008;79:578-84.

13. Proietti $E$, Röösli M, Frey U, et al. Air pollution during pregnancy and neonatal outcome: a review. J Aerosol Med Pulm Drug Deliv 2013;26:9-23.

14. Nordling E, Berglind N, Melén E, et al. Traffic-related air pollution and childhood respiratory symptoms, function and allergies. Epidemiology 2008;19:401-8.

15. Jedrychowski W, Perera F, Maugeri U, et al. Effects of prenatal and perinatal exposure to fine air pollutants and maternal fish consumption on the occurrence of infantile eczema. Int Arch Allergy Immunol 2011;155:275-81.

16. Aguilera I, Pedersen M, Garcia-Esteban R, et al. Early-life exposure to outdoor air pollution and respiratory health, ear infections, and eczema in infants from the INMA study. Environ Health Perspect 2013;121:387-92.

17. Rice MB, Rifas-Shiman SL, Oken E, et al. Exposure to traffic and early life respiratory infection: a cohort study. Pediatr Pulmonol 2014;50:252-9.

18. Esplugues A, Ballester F, Estarlich M, et al. Outdoor, but not indoor, nitrogen dioxide exposure is associated with persistent cough during the first year of life. Sci Total Environ 2011;409:4667-73.

19. Miyake Y, Tanaka K, Fujiwara H, et al. Residential proximity to main roads during pregnancy and the risk of allergic disorders in Japanese infants: the Osaka Maternal and Child Health Study. Pediatr Allergy Immunol 2010;21:22-8.

20. Harrod KS, Jaramillo RJ, Rosenberger CL, et al. Increased susceptibility to RSV infection by exposure to inhaled diesel engine emissions. Am J Respir Cell Mol Biol 2003;28:451-63.

21. Castranova V, Ma JY, Yang HM, et al. Effect of exposure to diesel exhaust particles on the susceptibility of the lung to infection. Environ Health Perspect 2001;109:609-12.

22. Magnus P, Birke C, Vejrup K, et al. Cohort Profile Update: the Norwegian Mother and Child Cohort Study (MoBa). Int J Epidemiol 2016;45:382-8.

23. Panasevich S, Håberg SE, Aamodt G, et al. Association between pregnancy exposure to air pollution and birth weight in selected areas of Norway. Arch Public Health 2016;74:26.

24. Beelen R, Hoek G, Vienneau D, et al. Development of NO2 and NOx land use regression models for estimating air pollution exposure in 36 study areas in Europe - The ESCAPE project. Atmos Environ 2013;72:10-23.

25. Pedersen M, Giorgis-Allemand L, Bernard C, et al. Ambient air pollution and low birthweight: a European cohort study (ESCAPE). Lancet Respir Med 2013;1:695-704.

26. Schisterman EF, Cole SR, Platt RW. Overadjustment bias and unnecessary adjustment in epidemiologic studies. Epidemiology 2009;20:488-95.

27. Gehring U, Gruzieva O, Agius RM, et al. Air pollution exposure and lung function in children: the ESCAPE project. Environ Health Perspect 2013:121:1357-64.

28. Miyake $\mathrm{Y}$, Tanaka K, Fujiwara H, et al. Residential proximity to main roads during pregnancy and the risk of allergic disorders in Japanese infants: the Osaka Maternal and Child Health Study. Pediatr Allergy Immunol 2010;21:22-8.

29. Canfield MA, Ramadhani TA, Langlois PH, et al. Residential mobility patterns and exposure misclassification in epidemiologic studies of birth defects. J Expo Sci Environ Epidemiol 2006;16:538-43. 
30. Madsen C, Gehring U, Walker SE, et al. Ambient air pollution exposure, residential mobility and term birth weight in Oslo, Norway. Environ Res 2010;110:363-71.

31. Muenchhoff M, Goulder PJ. Sex differences in pediatric infectious diseases. J Infect Dis 2014;209:S120-6.

32. Simoes EA. Environmental and demographic risk factors for respiratory syncytial virus lower respiratory tract disease. $J$ Pediatr 2003;143:118-26.
33. Cyrys J, Heinrich J, Richter K, et al. Sources and concentrations of indoor nitrogen dioxide in Hamburg (West Germany) and Erfurt (East Germany). Sci Total Environ 2000;250:51-62.

34. Cyrys J, Eeftens M, Heinrich J, et al. Variation of NO2 and NOx concentrations between and within 36 European study areas: Results from the ESCAPE study. Atmos Environ 2012;62:374-90. 